\title{
Bodies, Medicine and Otherness
}

\author{
Emilie Cloatre
}

\begin{abstract}
In this chapter, I explore how I would approach the hypothetical exercise of writing a chapter for a book on 'Law and the Body'. As a socio-legal scholar whose work is mostly on issues of law and medicine, the theme of the book would echo quite closely much of the focus of my work. Yet, I have not to date engaged as explicitly with the body as such a specific invitation would require. As a result, the exercise would be one of thinking through a new lens about my ongoing research, and empirical data, and engaging both familiar and less familiar questions and resources. In this piece, I try to chart what the process and its outcome may look like, proposing that my focus would be on a particular series of empirical questions that have emerged as I researched the regulation of traditional healing in Senegal.
\end{abstract}

Keywords Traditional healing $\bullet$ Medicine $\bullet$ Medical anthropology • Senegal • STS • Socio-legal

\section{INTRODUCTION}

My research mainly focuses on the interface between law and medicine: writing a paper on bodies would therefore be fitting. Even though I tend to identify primarily as a socio-legal scholar, I engage almost as heavily with other disciplines in which bodies occupy a central place (medical anthropology and sociology, global health, and, to a more minor extent, the history of medicine). Yet, thinking about bodies (or indeed making my research speak to this

E. Cloatre $(\bowtie)$

University of Kent, Canterbury, UK

e-mail: e.cloatre@kent.ac.uk 
particular thematic) has been less central to my work than engaging with the knowledges, institutions, and relationships that underpin the practice of medicine(s) and its regulation. Writing a chapter explicitly about bodies and law would invite me to approach my research from a new angle, or at least with a different emphasis. Like most interdisciplinary scholars, how I approach such an invitation would depend on the particular audience I am addressing, and the other contributions to the volume. For the purpose of 'thinking through', I will chart here what would be my approach to a volume in which scholars are invited to specifically unpick the relationship between bodies and law across thematic fields, and where the intended audience has a particular interest and expertise in law.

\section{LaW, Medicine, And the Body}

Even though most of my writing is based on empirical work, as I commence, I usually approach the exercise of writing with a broader context in mind. The work I sketch out below, for example, fits into a more general set of questions relating to the interface between law and medicine and their relationship to the body. Regulations, both within medical law and beyond, contribute to hindering or facilitating the making of 'healthy bodies'. However, the ways in which the translation from legal rules to everyday practice happens often escape the attention of regulators, as those constrained by such rules use their imagination to redefine the form and boundaries of their practice. At the same time, the making of regulations that surround medicine involves complex choreographies where scientific knowledge (or what counts as such) gets translated into political and legal choices and regulatory decision-making. In these processes, everyday health practices, themselves rooted in institutional and cultural histories, come to reshape how legal regulations are implemented, challenged, evaded or reimagined. In many ways, these questions provide fertile insights into broader societal patterns that my research tries to unpack. These processes also lend themselves to empirical inquiries in order to unearth some of the minute ways into which translations and transformations happen in everyday practice.

To approach a chapter on 'law and the body', and because the theme is so close to my own work, I would build on my existing (or ongoing) data to speak to the thematics of the book. At the moment, my main project explores how different legal systems regulate what we may label as 'alternative/complementary' or 'traditional' medicines - in effect, practices and therapies that differ from biomedical paradigms in some fundamental way and often sit on the edge of the main state-sanctioned systems of healthcare. ${ }^{1}$ This is a topic that has been of interest to me both because of the intrinsic challenges it raises and because of the broader phenomena that it can bring to mind. Healing systems have long and messy histories, and their place in healthcare has been shaped by

\footnotetext{
${ }^{1}$ This project is supported by the Wellcome Trust [grant 200380/Z/15/Z].
} 
the emergence of state medicine and the legalisation of some types of techniques, of training, and of materials rather than others (Ramsey, 1999; Wahlberg, 2007; Langwick, 2011). Law is and has always been central to delimiting the boundaries of legitimate healthcare: from the regulation of professions to that of materials, to the determination of where interventions over the body may be considered as tolerable for the purpose of healing, and where they should be considered as only harmful, law plays a central role in establishing the formal boundaries of practice. Healing practices, however, are also deeply rooted in societal configurations: scholars have long pointed to the gendered and racialised tensions that animate biomedicine, and decisions over how other forms of healings are legitimised or delegitimised echo these questions (Vaughan, 1991; Adams, 2002; Ehrenreich \& English, 2010). Traditions in healing are also deeply cultural and build on long histories of local tensions within populations, or superimposed over them, maybe most strikingly so in the colonial and postcolonial context (Wahlberg, 2006; Bivins, 2010; Vasconi, 2016). The question of how practices that sit on the edge of medicine should be regulated therefore speaks to much broader phenomena: what (and whose) knowledge matters for the purpose of regulation, how do different regulatory and medical systems deal with those who dissent, and what kind of effects does the interface between biomedical and legal institutions have on other healing (and cultural) practices?

Unpacking how healing paradigms are accounted for in law and policy—and exploring how lines are drawn between those that are supported, those that are simply tolerated, and those that are more actively considered illegal and/or illegitimate - also raises fundamental questions about how states choose to balance societal and personal freedoms in healing (and often, in beliefs) and the universal claims of medical science (Cloatre, 2019). They also highlight the challenges of determining how to prove efficacy for medical and regulatory science: if clear paths have been established to determine if pharmaceuticals or vaccines work (even if they may remain contested), these are more blurry when healing relies on less standardised or measurable entities (such as raw plants) (Urquiza Haas \& Cloatre, 2021). Those who see incantations as part of their healing process, or believe that the relationship between healer and patient is central to the act of healing, will face yet more robust obstacles in seeking to prove that the practice they embrace 'works' (Adams, 2002). The reliance of biomedicine on the assumption that minds and bodies are separate spheres of existence and that ways of healing need to be proven through bodily evidence has been largely embraced by regulatory logics. Yet, numerous healing practices continue to rely on a very different cosmology and a different bodily ontology. Even where laws do not explicitly privilege one type of ontology over others, the powers given to biomedical institutions to police the boundaries of healing practices may have similar effects.

Making sense of how various healing practices coexist with biomedicine, and how they are influenced by specific regulations and legal systems (in a more generic sense), therefore speaks to how law accommodates different cultural 
understandings of how bodies function (as materials). In my own work, I approach these questions through interdisciplinary methods at the crossroad of law and the social sciences, building in particular on some of the key questions that Science and Technology Studies (STS) engage in relation to the making of scientific (and other) knowledge and its social construction. In approaching a particular chapter or piece of writing, I might take much of this for granted, yet it underpins my particular interest in the production of knowledge and its expression through social relations and institutions, and indeed its effects on social inequalities, which is particularly striking in the context of biomedicine. As I approach the chapter sketched out below, this broader picture and particular standpoints would frame my thinking, shaping both what I am likely to consider would be an interesting topic to share with others, but also the kind of issues that I am most likely to pick up-or indeed produce-through my data.

\section{Methodology: What Story to Tell?}

The chapter I would be writing on the body would build onto the stories that my project on law and alternative/traditional medicines has produced so far. This project, like much of my previous work, relies on qualitative research methods. It is also built on a series of case studies, in Western Europe (France and England), West Africa (Ghana and Senegal) and the West Indian Ocean (Mauritius and La Réunion): rather than imagining these as purely comparative, my approach is rooted in the assumption that research-empirical or otherwise - can only provide particular snapshots of much broader and multiple realities. In this project, none of these case studies is expected to give a complete and definite picture of what law means for traditional medicine, or vice versa. Instead, I am interested in juxtaposing snapshots in order to illustrate some of the frictions that arise when states seek to regulate alternative and/or traditional healing. While some of these are constant across case studies (e.g. the difficulty of creating regulatory order when the tests and logics of science do not map onto the ontological and epistemological claims being made), others are the result of social and cultural particularities.

Given the scale of the project and of the data that it has produced, a chapter on the body could build on almost any case study, as well as cut across them to produce a more general and maybe more conceptual overview of what looking at law and traditional medicine as a global set of relationships can suggest in terms of questions of rights over both sick and healthy bodies. This would be one of the first choices to be made upon receiving the invitation, and a translation of a general 'what do I want to write about/what do I have to say about this' question. It would determine the balance between empirical nitty-gritty details and conceptual framing, but would also need to account for the audience: if the detailed history or social experience of a particular healing practice, or particular healing bodies, in relation to regulation might be of interest to those who work on similar topics in medical anthropology or sociology, legal 
scholars may find it more pertinent to think about how the area can help us continue to make sense of the type of social practice that we label 'legal' and its embodied translations. Inevitably, the final choices would also be about timings and may be slightly opportunistic: which set of data I am most embedded in at a particular time might determine which story I end up deciding to tell.

Because I am currently working on data from Senegal, if I were invited to write a chapter on the body today, it is likely that I would focus my chapter on how broader questions from the project are playing out in this particular context, and particularly on how the boundaries of legal healing are defined. One particular puzzle I may focus the chapter on is how the work done by legal and biomedical institutions comes to construct particular lines of tolerance, whereby healers are tolerated only insofar as their practice does not look too much like biomedicine, yet, at the same time, are expected to demonstrate the scientific rationality of their work. I return to this in some detail below, but first I set out the more general picture that makes this specific focus pertinent-or at least the most obvious direction in which to take the proposed chapter. Thinking through the policing that takes place over healing in Senegal, and who gets to determine how traditional healers can interact with bodies while remaining within the sphere of legal healing, would be an example of the kind of snapshot that I hoped to obtain through my case studies, echoing broader questions around how legal and biomedical institutions jointly shape the boundaries of healing, while at the same time reflecting the socio-historical particularities of Senegalese health practices and health governance.

The chapter, as is the case for each of the case studies in my project, would build on in-depth interviews, some observation, and documentary materials. Data collection was a collective endeavour, and I have benefited from the support of a team of researchers in carrying out this work, particularly since the Covid crisis made international travel impossible. As a result, the proposed chapter would almost definitely be co-authored: the ideas I am sketching here would be my proposal to colleagues, and the final chapter would inevitably be reshaped by our collective conversations. The data on which we would build aimed to try to understand debates both from the top-down (how governments and regulators have approached alternative and traditional medicine) and from the bottom-up (how actors who practise and/or promote alternative and/or traditional medicine have engaged with state regulation, and what normativities they have deployed alongside it to order their own practice). At the same time, the analysis aims to place this empirical material in its historical and social context, trying to make sense of the ways in which practices (both of regulation and of healing) have evolved over the years, including how colonial histories have influenced contemporary relations.

If part of the process of data collection has been to unearth some factual information-such as legal texts, formal statements by institutions, official positions of individuals or organisations - it has been, maybe more crucially, about documenting perspectives and experiences. This latter subjective dimension of qualitative research is both its limitation and what makes it, in my view, 
most valuable: there is no escaping the fact that what emerges are always partial stories, shaped by the particular voices of others, and this impacts the writing process to follow. The story is never complete and inevitably always limited to those voices that were heard. Truths are contested, and even what might be taken as a 'factual' starting point usually unravels as it is contextualised and commented upon. Accumulating further data might bring resolution on some matters, but for most others this fluid nature is the effect of the multiplicity of the social world itself on which one singular story can never be superimposed. Even with those limitations, however, empirical work is what puts flesh into (at least my own) understandings of how law operates in everyday lives, and what kind of visions it fosters, acknowledges, or seeks to supersede.

As I start planning the chapter, I would begin by thinking about how to segment the stories that have emerged from empirical data and reflect on whether they speak to the particular theme of the book. But the process also works the other way: starting with a specific focus on bodies in mind would shape how I approached the data, nudging me to pay attention to statements or phrasings that may not have jumped out otherwise. Writing and analysing are inevitably co-productive.

\section{Conceptualising Data}

At the same time, contextualising and making sense of data requires a thorough engagement with other scholarly works. This is also what will make a particular piece relevant to a broader audience. In general, my work is in close conversation with thematic literature that has engaged with alternative and traditional medicines as socio-cultural phenomena. For the proposed chapter, I would want to start by charting the key contributions from this scholarship that I build upon, before reflecting on what the particular stories from Senegal might add to what others have already explored. Traditional medicine is a very long-standing focus of sociological, anthropological, and historical work. Yet, law itself has rarely been the focus of this work, and the interaction of healing and legalities (and indeed their co-production) remains understudied. This affects both the audiences I would aim to speak to and the kind of work I could most productively build upon. My chapter would aim to address both a legal audience who may not have any particular interest in traditional medicine per se, but might find the broader questions around knowledge-making, regulations and institutions relevant, and an interdisciplinary audience of scholars with expertise in medical pluralism for whom thinking about how legal processes fit into the broader social processes at play may be of interest. At the same time, my chapter would build upon the work of others who have explored in depth the knowledge systems upon which different kinds of healing rest and, indeed, their understandings of the body and how those have been transformed, rewritten, reinvented, and/or preserved over the years (Fassin \& Fassin, 1988; Langwick, 2006, 2011; Osseo-Asare, 2014). It would also build on socio-legal scholarship, and in particular work that has interrogated the 
making of legalities through everyday practices, including through legal consciousness scholarship and anthropological explorations of legal relationships (e.g. Ewick \& Silbey, 1998; Mezey, 2001; Silbey, 2005).

This would provide some of the basic conceptual background for thinking through a particular story from Senegal that has intrigued me. Senegal, like many other African states, has a long history of medical pluralism: traditional practices vary across regions, overlap with religious traditions, and coexist with a biomedical system that is more accessible to some than to others. Traditional healing has not, to date, been explicitly regulated by the state, although a much-debated Bill is attempting to do just this at the moment. Given the opposition it has attracted from several circles, including the Ordre des Médecins, it is not clear, however, whether it will ever be successfully adopted. At the same time, traditional medicine is impacted by the law on illegal medical practice, a 1966 law, adopted on the model of previous colonial legislation, which organises the conditions of practice of medicine. One of the conditions it sets is that, to practise medicine legally, one must have a medical degree and be registered with the Ordre des Médecins. Anyone who carries out a medical act without meeting these conditions would be committing the criminal offence of 'exercice illégal de la médecine'. This is not to say that anyone doing 'healing' is doing so illegally: much hinges on the contentious definition of what constitutes a medical act. To a large extent, this definition has been left to the professional associations of biomedical practitioners-the Ordre des Médecins in particular-who tend to be the groups initiating complaints and denunciations that lead to the occasional prosecution of healers. A certain tolerance towards traditional healing, together with an understanding that traditional healers operate in a different sphere to that of biomedicine, means that many traditional healers never cross the boundary that would bring them to court. But, occasionally, those boundaries are crossed, and the Ordre des Médecins decides to intervene. In our interviews, one such boundary came up repeatedly and could form the starting point of my proposed chapter. Some contemporary healers, keen to use all the resources they can to diagnose their patients, occasionally send them out to undertake biomedical tests-X-rays, blood tests, ultrasounds, and so on. They ask their patient to return with the results of the test so that they can then proceed to offer traditional remedies. For the Ordre des Médecins, this is a clear infringement into the territory of biomedicine and one scenario in which the law on illegal medical practice is relevant, and this is a common ground for initiating legal procedures. Healers are aware of and have adapted to such risk: they are cautious in suggesting rather than prescribing medical tests, often ask patients to write down details of the test to be requested, rather than write it themselves (so that it is harder to claim that the test was 'prescribed' by the healer), and overall try to avoid being seen as the ones to initiate a demand for diagnostic test. A careful choreography ensues, where practitioners operate along very fragile lines of legality and legitimacy, and the law itself becomes translated through a tacit form of everyday negotiation. 
There is much in this seemingly simple story that I would like to unpack. Some of the practices at stake echo what others have demonstrated of the difficulty of defining 'traditional' healing, as traditional healers often borrow techniques and tools from a range of knowledge systems, transforming and reinventing themselves to fit the needs and opportunities of particular times (Hampshire \& Asiedu Owusu, 2013; Pordié \& Gaudillère, 2013). Interactions between traditional medicine and biomedicine also fluctuate-overlapping occasionally as here-while also creating new frictions. Here, these relationships become complicated by the pre-existence of legal tools that effectively enable biomedical institutions to monitor the boundaries of their professional monopoly, delimiting what they consider as being unacceptable intrusions and, in that process, framing the possibilities that are open to other traditions. In the context of Senegal, as in others, this particular use of the law also finds its roots in colonial histories: even if the 1966 law is particular in its phrasing and application to Senegal, its roots are in French law and its import during the colonial period. Similarly, the current structure of the Ordre des Médecins is in part a legacy of the colonial era. This also fits into much broader historical relations between agents of colonial states and local healers, and between local populations and colonial doctors, that constitutes an important background to understanding any question surrounding the governance of healing, as well as patterns of resistance, avoidance or engagement with state law, and indeed the importance of defining legally what different agents can and cannot do (and who gets to draw those lines). More than an abstract set of encounters between 'biomedicine' and traditional healers, the legal boundary-setting that takes place in Senegal is about institutional power and the significance of the Ordre des Médecins in determining what is acceptable or not.

I would also want to reflect on why tools of diagnosis are a particularly contentious issue. Usually, such boundary-setting by biomedical institutions hinges on notions of risk, for example, when products are given as treatment by unqualified practitioners. This is less explicit in this case, where the concern is arguably over an act of 'knowing' rather than 'doing'. At the same time, a fear often attached to non-biomedical healing is that patients who turn to alternative or traditional healing are driven away from biomedicine itself: arguably, this turn to biomedical diagnostic tools could be a way to facilitate the interface between two systems between which patients navigate. Tentatively, it seems that the concern at stake is one of blurring the boundaries between what should (at least for the Ordre des Médecins) remain clearly distinct systems, with different ways of both diagnosing bodies and ultimately treating them. Letting traditional healers use diagnostic tools suggests an intrusion onto the epistemological resources of biomedicine and the expression of a different kind of knowledge over the body which makes them potentially more problematic in the eyes of biomedical institutions.

In order to make sense of this, I would need to return to other analyses of the interactions between biomedicine and traditional healing, with a view to interrogating the kind of conditions that need to be placed upon traditional 
healing in order to make it 'tolerable' for biomedical institutions. Returning to the empirical data from Senegal would also give me a more detailed reading of how different actors seem to frame this particular issue. Yet, neither scholarly analyses from other contexts nor empirical data will give definite answers as to why this particular issue has become a sticky point in the application of the law, and one where illegal medical practice affects traditional healing. The reading I would be proposing would inevitably carry a degree of interpretation, grounded on multiple resources to try to make sense of the stakes of a particular debate.

\section{Thinking About Law}

As I think through these issues, I would also keep in mind broader questions about law - its nature and modes of action and what it can be seen to do in this particular story, which ultimately are always part of the puzzles I want to engage with. Essentially, the story at stake here is one of the interactions between law and particular knowledges and their mediation through institutional arrangements. At their core, legal decisions about which healing practices are considered as legitimate or not tend to build onto claims over the rationality of different kinds of knowledge systems. But the relationships between law and alternative or traditional healing also rests on multiple legal orders that not only become articulated in the everyday practice of healing, but also on the expression of law through very particular institutional translations of its principles: here, the Ordre des Médecins is a key source of influence in determining when the law should be triggered and how it should be mobilised. This is not uncommon and illustrates the often symbiotic relationship between law and biomedicine (and its institutions).

At the same time, other healers' relationship to formal state law is fragile. This requires healers to operate their own systems to determine what behaviours are acceptable or not and to adjust their practices to avoid having to encounter the force of the law, in both individual and collective ways, sharing experiences and learning from others' practices to limit their own precarity. This is not unique to this example, and forms of self-regulation are present in many of the practices that my project has considered. Such systems are never entirely cut-off from the law, sometimes acting 'instead of' state law, creating alternative systems to triage legitimate or non-legitimate healers, sometimes laying the groundings for future claims to be authorised or regulated. In the case of Senegalese healers and their use of diagnostic tools from biomedicine, practices are adjusted in response to a particular interpretation of the law. Legal effects go through a number of loops, travelling through the interpretation of biomedical doctors, back to prosecutors and courts, and back to individual healers themselves who adapt to ongoing pressures.

In this latter movement, the story of healers in Senegal also gives a snapshot of a broader concern that cuts across each of my case studies, speaking to the question of how those who sit on the edge of legality respond to the law and 
its interpretation. In Senegal, traditional healers have not received formal recognition by the state, in the way they have in neighbouring countries. Yet, there, as in other contexts where healers have not received legal backing, they tend to engage with the law, at least to some degree. The choreographies that healers devise to continue to use biomedical diagnostic tools while remaining under the radar of the Ordre des Médecins are part of a broader picture of coexisting with the law and the everyday tactics that limit their legal precarity. In these processes, healing practices themselves are affected: healing techniques are adjusted, professions reinvented and interactions redefined so that frictions with the formal legal system remain limited. This happens alongside ongoing negotiations for legal recognition, which matters more to some healers than others, and is also only seen as acceptable if it does not involve yet further oversight from biomedical doctors. One of the key stakes of legal recognition is the extent to which the acceptance of alternative ontologies by a legal system that has closely operated with and through biomedical institutions would require further taming and transformation. When drafting the chapter, I would need to think carefully about where to draw boundaries around the story, and whether the story of how illegal medical practice is enacted in particular ways can be told without also engaging broader questions around the negotiation of legal status for traditional healers.

As far as analytical resources are concerned, and to make sense in particular of the stories of law at stake, I would start by reaching out to STS-inflected work that has drawn on ideas of relationality and materiality to approach the messiness of everyday social practices (Latour \& Porter, 1993; Law \& Mol, 1995; Mol, 2003). This is the main theoretical tradition that I have relied upon in my work to date and where my expertise lies. Like for most scholars, this is in part the effect of my own training and 'where I come from' academically, and it continues to influence how I approach particular matters. At the same time, those perspectives echo how I tend to see the world and the type of puzzles that I want to think through in my work-micro-practices through which much can be learned about how social relations operate. This is also the set of perspectives that I started from when designing my current projects, and that have quietly shaped, in the background, the type of questions, type of literatures and types of networks I have attached the project to. For the same reasons, STS work would also be my starting point to think about the making - and policing - of knowledge and the role of particular institutions in producing and maintaining power over knowledge (Bora, 2008; Epstein, 1996; Jasanoff, 2006). Of course, legal relations themselves are rarely at the core of STS research, so, although the methodological tools help me decentre and 'flatten out' the legal as part of broader social relationships, I build onto more explicitly 'legal' scholarship to reflect on what my data suggests about our more general understanding of law. Thinking about the practice of coexisting with the law as an 'everyday' experience, which has emerged from much of the data on which I would build, echoes concerns cutting across legal anthropology, in particular those related to 'legal consciousness' and the law of the 
everyday, as well as scholarship on everyday illegality (Roitman et al., 2006; De Genova, 2013; Cloatre \& Enright, 2017). In addition, underlying much of the tensions at stake between doctors and healers is the question of otherness, and what kind of otherness is tolerated: here, it is a form of otherness that seems tolerable only as long as it remains within its own sphere, without tentatively crossing boundaries of knowing. Both feminist and postcolonial scholarship on science and the patterns of uneven power that organise relationships between states and scientific institutions would provide some pointers towards the making of such boundaries of legitimacy across law and (bio)medicine (Harding, 1991, 1998; Haraway, 1994, 2007). Finally, because the particular story I would like to explore is so centrally about institutions, the decentralisation of mechanisms of legal governance and the interface between socio-political power and biomedical knowledge, it may be that I would need to venture into the less familiar (to me) territory of governmentality and biopolitics. But I would very much see each of these engagements as being at least in part about making sense of the empirical story.

\section{Writing}

The process of writing the chapter itself would involve huge amounts of back and forth, between data and literature, and indeed many drafts and iteration. I find writing - and writing from data in particular-a difficult process: drawing the boundaries of the story, deciding which details to give and which may just be tedious to the reader, what to foreground and when, how much background to give, these choices always create infinite dilemmas. Writing a chapter for a thematic edited collection, rather than a standalone paper, also has its own challenges: here, focusing on bodies as a starting point, rather than what tend to be my more familiar 'starting points' (healers, healing practices, or materials such as medicinal plants) will require some rethinking of both data and literature in some of the ways I have suggested. Indeed, in the story I have presented here, bodies may still be more discrete than they would need to be to echo the particular focus of the book. Writing from data has its practical challenges-not only in terms of if and how to use direct quotes or not, how much theorising to do with the raw data itself, but also how to 'do justice' to the stories offered by informants. Writing about activities that are 'technically illegal' brings its own challenges, including in striking the difficult balance between describing and seemingly denouncing. In writing about these issues, my main aim is to convey perspectives and frictions, rather than polemics: ultimately, my work is not about whose understanding of the body is 'correct' (though in this sensitive field one is always aware that words can be interpreted to fit other agendas).

Writing in this field is also complicated by an ethical awareness of some of the abuses that have permeated healing over the years, reflected in each of our case studies that go beyond ontological tensions, and break away from a common sense of ethics that is not exclusive to biomedicine. If regulating healing practices is often centred on how to 'catch' abusive practices in the net of law, 
my work is concerned with all the other things that such legal strategies do, and the excesses in Othering that they produce. Engaging with these excesses, and those who challenge them, while remaining aware of the possibility of risk and abuse that needs to be also accounted for, requires careful writing. Often, however, those whom I have met in my research address these questions in their own words: they are aware of the risk that the field of healing creates and are keen to draw boundaries. Yet, they also want to propose alternative means of thinking of bodies and the act of healing in ways that are not limited to the perspective of biomedicine. They suggest approaches that are often not only about knowledge but also about politics. In Senegal, as elsewhere, healers and their users confront the state with some powerful questions about how we treat bodies, in every sense of the word. They are also agents who operate, regardless of what the law will do, and develop their own sense of ethics. Yet, they remain aware that some practices use similar discourses to propose something very different and potentially more abusive: stories of healers that have exhorted vast amounts of money, injured or physically abused patients, are also part of the field and those individuals risk discrediting the others. What makes the regulation of this field difficult also makes writing about it challenging: any sentence that recognises the multiplicity of healing ontologies (not only in Senegal but also, for example, in the contexts of France or England when talking about alternative healing) and the bodily ontologies underlying them could also be misconstrued as supporting the wildest claims that the most caricatural 'quacks' would make. This is, of course, one of the challenges of STS work in general: acknowledging the limitations of science as a provider of unique truth and rationality can easily be misconstrued as claiming that anything goes.

In addition to all these challenges, the act of writing itself is unpredictable. No matter how neat an idea may initially seem, it can get messy as it unravels: in my career to date, the papers that took longest to come together are not the ones that I had initially thought would prove most difficult, and vice versa. Usually, having a clear sense of what story a chapter will tell, or having in mind a particular empirical story that will anchor the chapter, tends to make the process easier. But I have found myself drowning in a fast-unravelling narrative too many times to ever approach the process of writing with calmness nor confidence.

Finally, the process I have focused on assumes a certain degree of abstraction. I have left aside the kind of practical questions and challenges that, in real-life academia, often complicate the processes of publishing and of writing. These include workload and the ability to take up offers or give to particular papers the time and attention they need, while staying within the constraints of multiple deadlines. It also includes a degree of prioritising and strategizing. I am privileged to be in a position where I receive ample time and support for my research, and do not have the pressures of thinking about promotions anymore. This has changed how I approach writing, including the sense of stress that it can create. Other pressures, however, continue to frame how I think about what piece of writing to accept or not (from decisions about the REF to 
ensuring that I deliver on what I had promised to my research funder). Here, I have imagined the invitation as one that I would accept and would be able to approach with enough time to be 'calm and composed': the real-life version of this process is likely to feel more rushed, more stressful, and more riddled with self-doubt than its imagined version.

\section{REFERENCES}

Adams, V. (2002). Randomized Controlled Crime: Postcolonial Sciences in Alternative Medicine Research. Social Studies of Science, 32(5/6), 659-690.

Bivins, R. (2010). Alternative Medicine?: A History. Oxford University Press.

Bora, A. (2008). Scientific Norms, Legal Facts, and the Politics of Knowledge. In N. Stehr \& B. Weiler (Eds.), Who Owns Knowledge? Knowledge and the Law (pp. 67-86). Transaction.

Cloatre, E. (2019). Law and Biomedicine and the Making of "Genuine" Traditional Medicines in Global Health. Critical Public Health, 29(4), 424-434.

Cloatre, E., \& Enright, M. (2017). "On the Perimeter of the Lawful": Enduring Illegality in the Irish Family Planning Movement, 1972-1985. Journal of Law and Society, 44(4), 471-500.

De Genova, N. (2013). Spectacles of Migrant "Illegality": The Scene of Exclusion, the Obscene of Inclusion. Ethnic and Racial Studies, 36(7), 1180-1198.

Ehrenreich, B., \& English, D. (2010). Witches, Midwives and Nurses. The Feminist Press.

Epstein, S. (1996). Impure Science: AIDS, Activism and the Politics of Knowledge. University of California Press.

Ewick, P., \& Silbey, S. S. (1998). The Common Place of Law: Stories from Everyday Life. University of Chicago Press.

Fassin, D., \& Fassin, E. (1988). Traditional Medicine and the Stakes of Legitimation in Senegal. Social Science and Medicine, 27(4), 353-357.

Hampshire, K. R., \& Asiedu Owusu, S. (2013). Grandfathers, Google, and Dreams: Medical Pluralism, Globalization, and New Healing Encounters in Ghana. Medical Anthropology, 32(3), 247-265.

Haraway, D. (1994). A Game of Cat's Cradle: Science Studies, Feminist Theory, Cultural Studies. Configurations, 2(1), 59-71.

Haraway, D. (2007). Situated Knowledges: The Science Question in Feminism and the Privilege of a Partial Perspective. In K. Asdal et al. (Eds.), Technoscience: The Politics of Intervention (p. 109). Unipub.

Harding, S. G. (1991). Whose Science? Whose Knowledge? Thinking from Women's Lives. Cornell University Press.

Harding, S. G. (1998). Is Science Multicultural?: Postcolonialisms, Feminisms, and Epistemologies. Indiana University Press.

Jasanoff, S. (2006). Ordering Knowledge, Ordering Society. In S. Jasanoff (Ed.), States of Knowledge: The Co-Production of Science and Social Order. Routledge.

Langwick, S. (2006). Geographies of Medicine: Interrogating the Boundary Between "Traditional" and "Modern" Medicine in Colonial Tanganyika. In T. J. Luedke \& H. G. West (Eds.), Borders and Healers: Broking Therapentic Resources in Southeast Africa (pp. 143-165). Indiana University Press.

Langwick, S. (2011). Bodies, Politics, and African Healing. Indiana University Press.

Latour, B., \& Porter, C. (1993). We Have Never Been Modern. Harvard University Press. 
Law, J., \& Mol, A. (1995). Notes on Materiality and Sociality. The Sociological Review, $43,274-294$.

Mezey, N. (2001). Out of the Ordinary: Law, Power, Culture, and the Commonplace. Law and Social Inquiry, 26, 145-167.

Mol, A. (2003). The Body Multiple. Duke University Press.

Osseo-Asare, A. (2014). Bitter Roots: The Search for Healing Plants in Africa. University of Chicago Press.

Pordié, L., \& Gaudillère, J.-P. (2013). Industrialiser les médicaments ayurvédiques: les voies indiennes de l'innovation pharmaceutique. Autrepart, 63(4), 123-143.

Ramsey, M. (1999). Alternative Medicine in Modern France. Medical History, $43(3), 286-322$.

Roitman, J., Comaroff, J., \& Comaroff, J. (2006). The Ethics of Illegality in the Chad Basin. In J. Comaroff \& J. L. Comaroff (Eds.), Law and Disorder in the Postcolony. University of Chicago Press.

Silbey, S. S. (2005). After Legal Consciousness. Annual Review of Law and Social Science, 1, 323-368.

Urquiza Haas, N., \& Cloatre, E. (2021). The Challenge of "Evidence": Research and Regulation of Traditional and Non-Conventional Medicines. In G. Laurie et al. (Eds.), Cambridge Handbook of Health Research Regulation. Cambridge University Press.

Vasconi, E. (2016). Witchcraft, Medicine and British Colonial Rule: Anthropological Analysis of Colonial Documents in the Gold Coast. In M. Pavanello (Ed.), Perspectives on African Witchcraft. Routledge.

Vaughan, M. (1991). Curing Their Ills: Colonial Power and African Illness. Stanford University Press.

Wahlberg, A. (2006). Bio-politics and the Promotion of Traditional Herbal Medicine in Vietnam. Health, 10(2), 123-147.

Wahlberg, A. (2007). A Quackery with a Difference - New Medical Pluralism and the Problem of "Dangerous Practitioners" in the United Kingdom. Social Science and Medicine, 65(11), 2307-2016.

Open Access This chapter is licensed under the terms of the Creative Commons Attribution 4.0 International License (http://creativecommons.org/licenses/ by/4.0/), which permits use, sharing, adaptation, distribution and reproduction in any medium or format, as long as you give appropriate credit to the original author(s) and the source, provide a link to the Creative Commons licence and indicate if changes were made.

The images or other third party material in this chapter are included in the chapter's Creative Commons licence, unless indicated otherwise in a credit line to the material. If material is not included in the chapter's Creative Commons licence and your intended use is not permitted by statutory regulation or exceeds the permitted use, you will need to obtain permission directly from the copyright holder. 